\title{
فاعلية المرونة النفسية على هرموني الروبامين والسيروتلين والمستوى الرقمي للسباحين الناشئين بلدولة الكويت
}

" أ.د/عادل محمل عبل|مالمنعم مكي

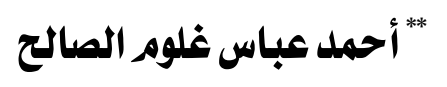

المقدمة ومشكلة البحث:

أصبح الإهتمام بالإعداد النفسي ووضـع برامج التدريب للمهارات العقلية والنفسية

يقف على نفس المكانة والأهمية لوضع برامج التدريب البدني والمهاري والخططي، حيث

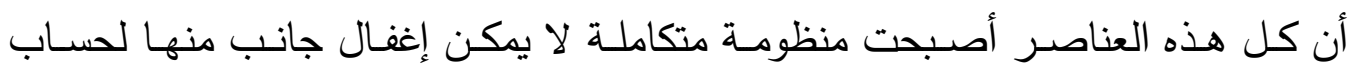
الجانب الآخر، ويكون الهدف النهائي من هذه المنظومـة المتكاملة هو تكوين اللاعب القادر على تلبية متطلبات الأداء الذي يمارسه مع إكسابه القدرات التي تمكنه من مواجهة هونة هونه

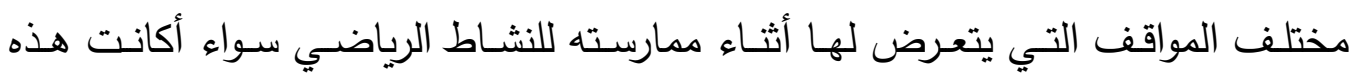
المواقف بدنية أو مهارية أو نفسية.

أن العديـد مـن الأخصـائيين النفسيين والمـدربين الرياضـيين أصسبحوا الأن أكثر

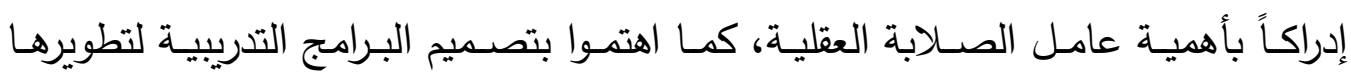

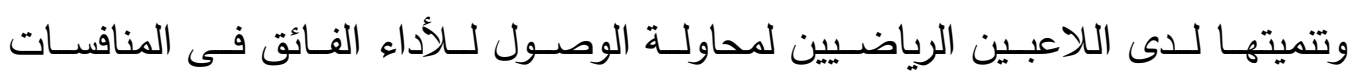

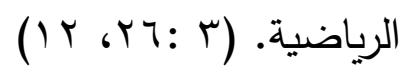

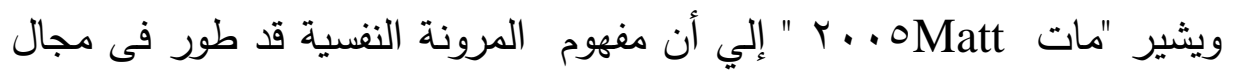

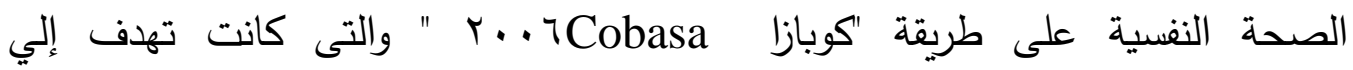
توضيح لماذا تبدو خبرة الضغوط على أنها حالة غير صحية لاى الغالبية العظمى من

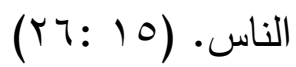

" أستاذ الإدارة الرياضية ووكيل كلية التربية الرياضية لشئون الدراسات العليا والبحوث- جامعة أسوان. "*" الباحث بقسم التدريب الرياضي - كلية التربية الرياضية - جامعة اسوان. 
ويبين "مدلتون VMiddelton . . . ץ" أهمية الجوانب العقلية المرتبطة بالأداء الرياضى الفائق ، و أشار إالي الصلابة العقلية وأهمية إمتلاكها للاعب للوصول إلي

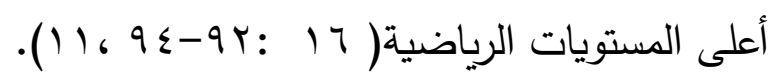

ويرى "سيمون ميدلتون وآخرون .Simon Middleton et al ؛ . . ץ" إلي أنها أقصى مستوى نفسي طبيعي أو متطور نستطيع الوصول إليه ، وهى تكسب الرياضيين قدرة على التحمل مقارنة بمنافسيهم أثناء التنافس الرياضي أو التدريب أو أسلوب التهئ الحياة ،

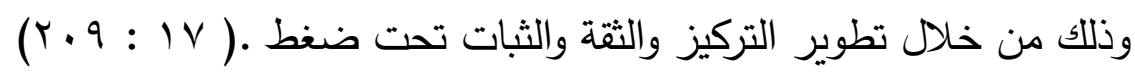

ويرى" محمد لطفى حسنين (T · . r م)" أن الإنجاز الرياضي يمثل قابلية التدريب ويقصد بة السعى والكفاح نحو مستوى معين من التفوق والإمتياز ، ويتحدد من خلال التتافس مع أخرين أو تتافس اللاعب مع ذاته بالمقارنة بالأداء السابق...فهو بذلك محاولة

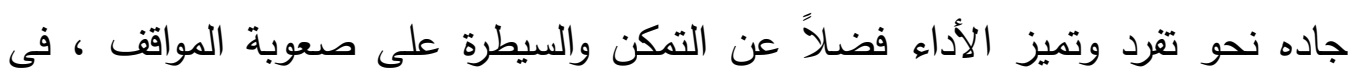
ضوء ذلك فإن الإنجاز الرياضي يمثل إستعداد فطري نحو إظهار قدر من مستويات

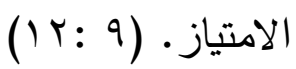

أن الانجاز الرياضي هو الالتزام فى التدريب مهما كانت درجة صعوبته وتنفيذ كافة تعليمات المدرب كدافع للسعى والكفاح نحو هدف محدد من التفوق، وتجري هذه هردي المنافسات واحدة بعد الأخرى في تتابع غير منقطع، ويتحتم على اللاعب إيجاد التوازن

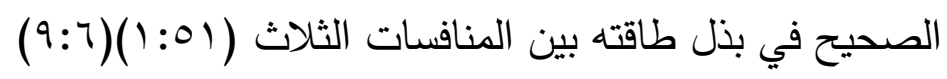

من خلال خبرة الباحث في لعبة السباحة حيث انه حقق العديد من البطولات منذ

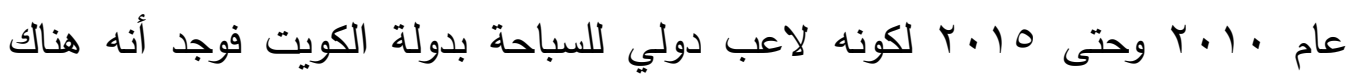

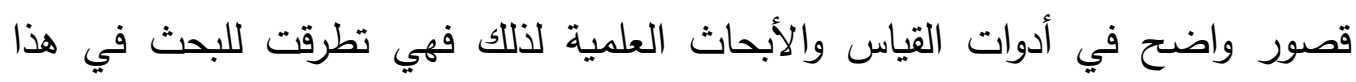
الموضوع ، وقد تبلورت فكرة البحث في ذهن الباحث من خلال ملاحظته للفروق الهائلة في مستويات الأداء بين المستويات العالمية والمستويات الكويتية وهنا تطرق في ذهن 
الباحث سؤال عن أسباب هذه الفجوة والتي قد تكون نتيجة افتقار لاعبينا إلى بعض المتغيرات التي تؤثر في الأداء والتي قد يكون منها نقص المهارات النفسية . بالإضـافة إلى ملاحظـة الباحـث أن اللاعبين المصـنفين دوليـا يـؤدوا المسـابقات التنافسية عادة بثبات عالي ولا يتأثروا بضغوط التنافس أو طبيعة وأهمية المنافسات. ومن خـلال الإطلاع على الشبكة العالمية للمعلومات (الانترنت) ، لاحظ الباحث قلة الدراسات التي تتاولت المرونة النفسية في المجال الرياضي عامة وفى مجال السباحة خاصـة ، وفى هذا الصدد يشير فولغام Fulgham, (ع . . F) إلى أن اغلب الدراسات التي أجريت في مجال تدريب المهارات النفسية اقتصـرت على المقارنـة بين الموهوبين

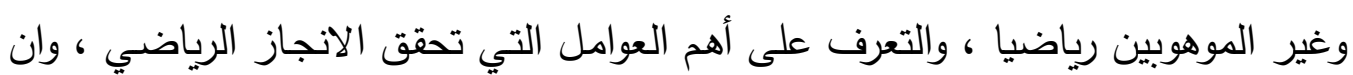
الدراسـات التي اهتمـت بكيفيـة إستخدام وتطبيق المهارات النفسية التي تعكس الصـلابة ولتية

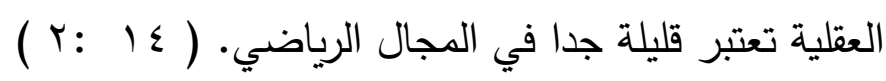
أهداف البحث:

يهذف هذا البحث إلي التعرف على فاعلية المرونة النفسية على هرموني الروبامين والسيروتلين والمستوى الرقمي للسباحين الناشئين بدولة الكويت.

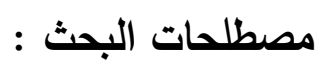

المرونة النفسية Resilience

هي قدرة الشخص على تحمل الضغوطات و المصاعب من غير حدوث مشاكل نفسية.)(1) (1) (1)

\section{: منهج البحث :}

اســخدم الباحـث المـــهج التجريبـي ذو المجمـوعتين( الضــابطة - التجريبيـة) باسـتخدام القيـاس القبلي والبعدي وذلـك لمعرفـة تـأثير المرونـة النفسـية على مسـتى دوى 
هرمــوني الروبــامين والسـيروتلين والمسـتوى الرقــي للســاحين الناشــئين ولملاءمتــهـ لطبيعة الدراسة .

عينة البحث :

\section{اختيار عينة البحث :}

تم اختيار عينة البحث من سباحي الصدر بنادي العربي الكويتي من سن(ء إن : T (1) سنة من المقيدين بالاتحاد الكويتى للسباحة وكان عدد السباحين ؟r سباحا ، وتم اختيار المجموعة المتميزة منهم لتكون عينة البحث وكانت ع ا سباحا ، وتم تقسيمه إلى مجموعتين متكافئتين\}ضابطة - تجريبية\{ بواقع ( V ) سباحين في كل مجموعة ، وتم تطبيق البرنامج التدريب(تدريبات المرونة النفسية) على المجموعة التجريبة خلال الموسم

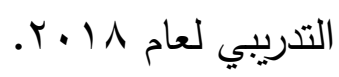

\section{خصائص العينة :}

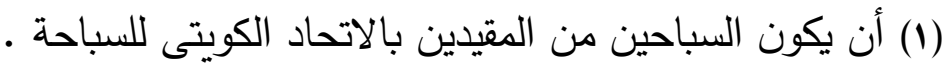

(r) أن يكون هناك تجانس بين أفراد العينة في متغيرات الدراسة السن - الطول - الوزن - الوثب العريض - الوثب العمودي - زمن سباحة . . ام صدر).

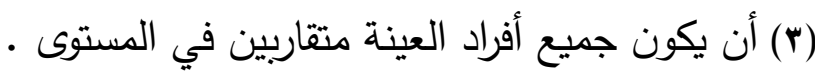

(§) أن يكون جميع أفراد العينة من السباحين المنتظمين في التدريب .

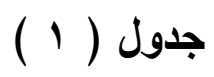

المتوسط والوسيط والانحراف المعياري والالتواء في القياس القبلي

\begin{tabular}{|c|c|c|c|c|c|}
\hline الالتواء & الانحراف & الوسيط & المتوسط & وحدة القياس & المتغيرات \\
\hline$\cdot, 1 \vee 0$ & $\cdot, 099$ & $1 \leqslant, 0$ & $1 \leq, 0 Y 0$ & سنة & السن \\
\hline$\cdot, q \cdot r-$ & r,041 & 170 & $17 r, q Y \wedge$ & سم & الطول \\
\hline
\end{tabular}

لاراسة التجانس في عينة البحث (ن = ع ( ) 


\begin{tabular}{|c|c|c|c|c|c|}
\hline$\cdot, r \cdot 1-$ & $\varepsilon, Y q r$ & $\bullet \vee, \vee \bullet$ & OV,rYI & 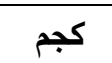 & 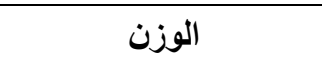 \\
\hline$\cdot, \leqslant 90$ & $q, q \mu r$ & 179 & $17 V, T \leq Y$ & 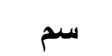 & الوثب العريض \\
\hline$\cdot, \leqslant \wedge \bullet-$ & $r, \cdot \wedge v$ & $\varepsilon$. & $r q, 0$ & 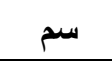 & الوثب العمودي \\
\hline$\cdot, 98-$ & $1, r \wedge$. & $\Delta \wedge, Y \uparrow$ & $\Lambda \bullet, Y \backslash 0$ & $\dot{ث}$ & زمن . 1 م سباحة صدر \\
\hline$\cdot, \mu l \varepsilon$ & $r, 70$ & $r \ldots,+1$ & $r_{1} \cdot, r q$ & مل مول & هرمون الروبامين \\
\hline$\cdot, Y \wedge \varepsilon$ & $r, r \wedge$ & $10 \cdot, \cdot r$ & $\mid 0 \leq, Y 1$ & مل مول & هرمون السيترولين \\
\hline
\end{tabular}

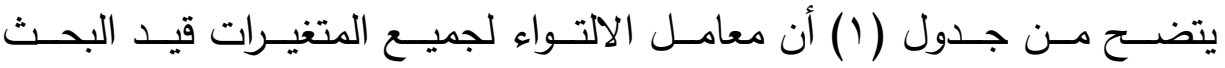

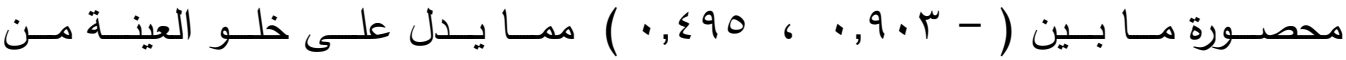
عيوب التوزيع الغير اعتدالي وتجانس العينة في المتغيرات قيد البحث . جدول (r) دلالة الفروق بين المجموعتين التجريبية والضابطة في متغيرات البحث

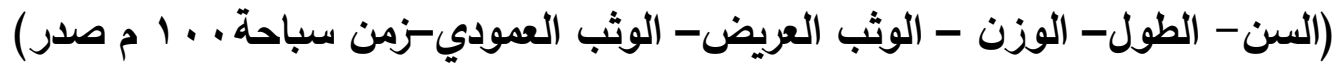
لاراسة تكافؤ مجموعتي البحث في القياس القبلي (ن= \& ا )

\begin{tabular}{|c|c|c|c|c|c|c|c|}
\hline \multirow{2}{*}{ الدلالة } & \multirow{2}{*}{ ف س } & \multicolumn{2}{|c|}{ الضابطة } & \multicolumn{2}{|c|}{ التجريبية } & \multirow{2}{*}{ وحدة القياس } & \multirow{2}{*}{ المتغيرات } \\
\hline & & $\varepsilon \pm$ & س س & $\varepsilon \pm$ & س س & & \\
\hline غير دالة & $\cdot, \cdot \times 1-$ & $\cdot, \sum \vee 1$ & $1 \leq, 0 \times 1$ & $\cdot, \sum \pi r$ & $1 \leqslant, 0$ & سنة & السن \\
\hline غير دالة & $\cdot, 1 \leq r$ & זיז,זי & $17 r, \wedge 0 V$ & $r, v \cdot r$ & $17 \varepsilon$ & سم & الطول \\
\hline غير دالة & $\cdot, \cdot r \wedge$ & $\varepsilon, \cdot \varepsilon r$ & OV, YOV & $\varepsilon, \Sigma V Y$ & $O V, Y \wedge O$ & كجم & الوزن \\
\hline غير دالة & $\cdot, 1 \leq r$ & 14,117 & $\mid 7 V$, OV1 & 7,001 & $|7 V, V| \leq$ & سم & الوثب العريض \\
\hline غير دالة & $\cdot, 1 \leq r$ & 0,191 & rq, हrᄉ & r,qVV & rq,ov1 & سم & الوثب العمودي \\
\hline غير دالة & $\cdot, \cdot \vee V-$ & 1,771 & $10,1 \wedge$ & $1, .1 r$ & $10, Y_{0}$ & $\dot{H}$ & "... م صدر \\
\hline غير دالة & $\cdot, 9 \wedge$ & $r, r$, & $r \cdot 0, r r$ & $\cdot, r \wedge$ & $r \cdot 9, r_{1}$ & مل مول & هرمون الروبامين \\
\hline غير دالة & $\cdot, r_{1}$ & $r, 01$ & $1+0, r_{q}$ & $\cdot, T \leqslant$ & $|r \wedge, r|$ & مل مول & هرمون السيترولين \\
\hline
\end{tabular}

قيمة ت الجدولية عند مستوى معنوية 0 ., =. = آץ, .

يتضح من جدول (r) أنه لا توجد فروق ذات دلالة إحصائية بين المجموعتين التجريبية والضابطة لمتغيرات السن والطول والوزن والوثب العريض من الثبات والوثب العمودي وزمن سباحة . . 1 متر صدر ، وهرمون الروبامين والسيروتلين مما يدل على تكافؤ مجموعتي البحث . 


\section{الاختبارات المستخدمة :}

(1) (1) اس الطول باستخدام جهاز الرستامير بالسنتيمتر ل

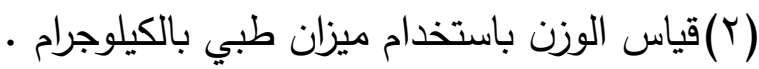

(r)(اختبار الوثب العريض من الثبات لقياس مسافة الوثب العريض بالسنتيمتر

(قياس القدرة العضلية للرجلين في الوثب العريض من الثبات).

(§)اختبار الوثب العمودي لسارجنت من الثبات لقياس مسافة الوثب العمودي

بالسنتيمتر ( قياس القدرة العضلية للرجلين في الوثب العمودي لأعلى ) .

(0)قياس زمن سباحة . . . متر صدر بالثانية .

(T) التحليل المعملي لهرموني هرموني الروبامين والسيروتلين

الأجهزة والأدوات : - الأل

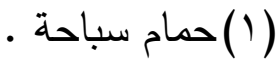

. (Y) (r)

(r)جهاز رستامير لقياس الطول ( سم ) •

(ع)ميزان طبي لقياس الوزن ( كجم ) .

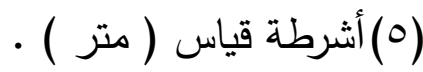

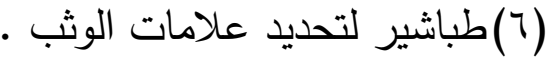

• صناديق الوثب ( ارتفاعات مختلفة ) )

. مقاعد سويدية

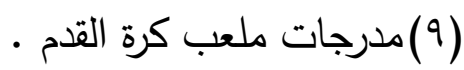

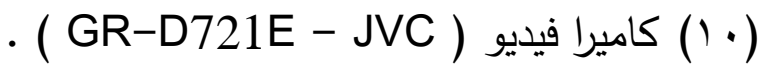

• ( PC 1231 - Canon ) ( Digital ) (1) 
قام الباحث باجراء القياس القبلي من خلال تطبيقين وذللك لدراسة ثبات الاختبارات

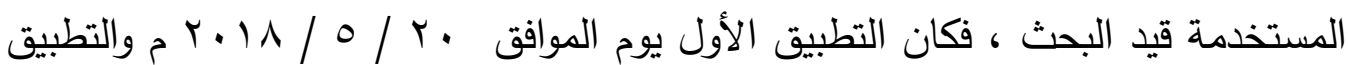

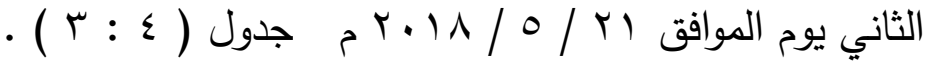

$$
\begin{aligned}
& \text { واشتمل القياس القبلي على : }
\end{aligned}
$$

(1) قياس الطول باستخدام جهاز الرستامير لقياس الطول بالسنتيمتر ، (1)

(r) قياس الوزن باستخدام ميزان طبي لقياس الوزن بالكيلوجرام . (r)

(r) اختبار الوثب العريض من الثبات لقياس مسافة الوثب العريض بالسنتيمتر

$$
\text { ( قياس القدرة العضلية للرجلين في الوثب العريض من الثبات ) • }
$$

(§) اختبار الوثب العمودي لسارجنت من الثبات لقياس مسافة الوثب العمودي

بالسنتيمتر ( قياس القدرة العضلية للرجلين في الوثب العدودي لأعلى ) .

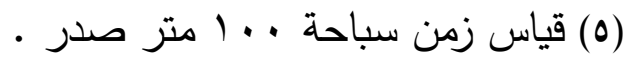

(7) التحليل المعملي لهرموني هرموني الروبامين والسيروتلين.

$$
\text { البرنامج المقترح للمرونة النفسية }
$$

الاراسة الأسساسية :

\section{الهرف من تمرينات المرونة النفسية :}

تنمية القدرة على اكتساب تركيز الانتباه عن طريق برنامج لتمرينات

المرونة النفسية ( العضلي ، العقلى ، التصورى )

تخفيض درجة التوتر عن طريق برنامج لتمرينات المرونة النفسية

(العضلي ، العقلي ، التصوري ) لدى منتخب السباحة لجامعة حلوان .

أسس وضع تمرينات المرونة النفسية:

• أن تتمشى تمرينات الاسترخاء (العضلي ، العقلي ، التصوري ) مع خصائص

$$
\text { ناشئي السباحة . }
$$

مراعاة عامل الآمن والسلامة أثناء تنفيذ الوحدة . التنوع في استخدام الأدوات المستخدمة في تمرينات المرونة النفسية. 
التوازن بين تمرينات المرونة النفسية في كل وحدة تدربية . • مراعاة مظاهر التعب وتخصيص فترات بينية قصيرة للراحة والمرونة النفسية أثناء

$$
\text { مكونات تمرينات المرونة النفسية التدية: . }
$$

تشتمل تمرينات المرونة النفسية على مجموعة من الأبعاد والمحاور الأساسية

$$
\begin{aligned}
& \text { وهى : } \\
& \text { المشي البطيء على جهاز السير المتحرك . } \\
& \text { تمرينات المرونة النفسية (العضلي - العقلي والتصوري ). } \\
& \text { • تمرينات التنفس }
\end{aligned}
$$

المدة الزمنية لتمرينات المرونة النفسية:

تم تنفيذ تمرينات المرونة النفسية لمدة (^) أسابيع وهى المدة الكلية لتمرينات المرونة النفسية بواقع ثلاث وحدات في الأسبوع بمجموع (؟؟) وحدة تدريبية وبمعل

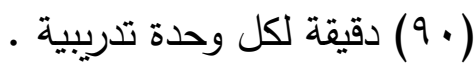
محاور وأبعاد تمرينات المرونة النفسية: تتأسس تمرينات الاسترخاء المقترحة على : المحور الأول : تمرينات المرونة النفية ويتضمن الأبعاد آلاتية : البعد الأول : الإسترخاء العضلي (التعاقبى) . البعد الثاني : الإسترخاء العقلي باستخدام ( الوعى بالأفكار السلبية ) . البعد الثالث : الإسترخاء التصوري • المحور الثانى : تمرينات التنفس. محتوى تمرينات الاسترخاء : المحور الأول : تمرينات الإسترخاء : البعد الأول : تمرينات الإسترخاء العضلي 
يمثل هذا البعد أحد الأبعاد في تمرينات الإسترخاء وقد تم استخدام الباحثة

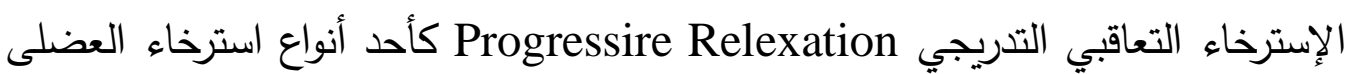
لتنفيذ هذا البعد والتي تتضمن أداء سلسلة من الانقباضات العضلية يتبعها استرخاء تام أى أنه يهدف الى التمييز بين الإنقباض والانبساط العضلي كمدخل للوصول إلى الإسترخاء العضلى العميق ، مع مراعاة أن يتم النقل من مجموعة عضلية إلى أخرى حتى لإصى يتم الإسترخاء في جميع المجموعات العضلية للجسم. والإسترخاء التعاقبي هو تعاقب الانقباض من مجموعة عضلية لأخرى حتى يغطى جميع المجموعات العضلية فى الجسم • البعد الثاني : الإسترخاء العقلي : استخدام الباحثة الإسترخاء العقلي باستخدام ( الوعى بالأفكار السلبية ) يعتبر

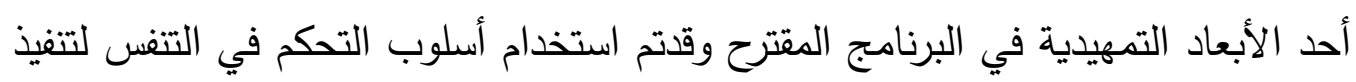
هذا البعد باعتبار أن مهارة التتفس العميق الصحيح هى المفتاح الرئيسي لاكتساب الإسترخاء العقلي والتحرر من التوتر والقلق وقد أعتمد ذلك على أداء مجموعة من هن ت تدريبات التتفس برن

البعد الثالث : الإسترخاء التصورى : أعتمد على مجموعة من التصورات التي تعتمد على إيقاف الأفكار السلبية ووضع مجموعة من العبارات الإيجابية .

المحور الثانى : تمرينات التففس : اشتملت على مجموعة من تمرينات التتفس التي تعتمد على التنفس البطني، التتفس الصدرى، التنفس السطحي، حبس النفس والدفع مع أخذ فترات راحة بين كل تلفي • تمرين وآخر تجربة البحث : ت تمرين 
قام الباحث بتطبيق تجربة البحث في حمام السباحة ومدرجات ملعب كرة القدم بنادي طنطا الرياضي واحدي صالات اللياقة البدنية بطنطا ، وكان زمن تطبيق البرنامج التدريبي ( r ) أشهر بواقع ( r r ) أسبوع ، (r ) وحدات تدريبية في الأسبوع الواحد ،

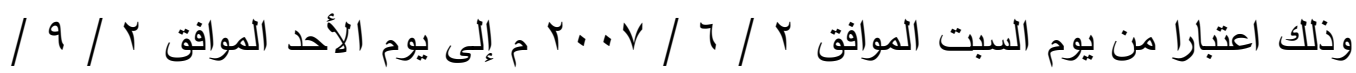

$$
\begin{aligned}
& \text { V.... . م مرفق رقم ( ) ). } \\
& \text { القياس البعدي : }
\end{aligned}
$$

قام الباحث بإجراء القياس البعدي يوم الأربعاء الموافق ه / 9 / V . . r م واشتمل

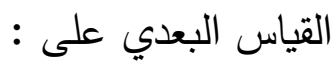
(1) اختبار الوثب العريض من الثبات لقياس مسافة الوثب العريض بالسنتيمتر (قياس القدرة العضلية للرجلين في الوثب العريض من الثبات). (r) اختبار الوثب العمودي لسارجنت من الثبات لقياس مسافة الوثب العمودي بالسنتيمتر (قياس القدرة العضلية للرجلين في الوثب العمودي لأعلى).

$$
\begin{aligned}
& \text { (r) قياس زمن سباحة . . . أمتر صدر • } \\
& \text { المعاملات الإحصائية المستخدمة : } \\
& \text { - - } \\
& \text { - الوسيط - } \\
& \text { - - الانحراف المعياري - } \\
& \text { - الالتواء - } \\
& \text { - T.test اختبار - } \\
& \text { - - التخطيط والأعمدة البيانية . } \\
& \text { جدول (1 - ع }
\end{aligned}
$$

\begin{tabular}{|c|c|c|c|c|c|}
\hline الدلالة & ت & ف س & بعدي & قبلي & الوثب \\
\hline
\end{tabular}

دلالة الفروق بين القياسين القبلي و البعدي للمجموعتين التجريبية و الضابطة

$$
\text { لمتغير الوثب العريض من الثبات (ن = ع الي ) }
$$




\begin{tabular}{|c|c|c|c|c|c|c|c|}
\hline & & & $\varepsilon \pm$ & س & $\varepsilon^{ \pm}$ & س & العريض \\
\hline دالة & $7, Y \leq 7-$ & $|V, V| \leq-$ & $\vee, \wedge \leq \wedge$ & $\mid \wedge 0, \Sigma r \wedge$ & 7,001 & $|T V, V| \leq$ & التجربيية \\
\hline دالة & $1,0 \mathrm{VV}-$ & $7, \wedge \circ \vee-$ & $9,90$. & $\mid \vee \varepsilon, \varepsilon Y \wedge$ & 14,117 & $17 V, O V 1$ & الضابطة \\
\hline \multicolumn{5}{|c|}{$\% 1 \cdot, 07 r$} & \multicolumn{2}{|c|}{ التجريبية } & \multirow{2}{*}{ نسبة التحسن } \\
\hline \multicolumn{5}{|c|}{$\% \varepsilon, .91$} & \multicolumn{2}{|c|}{ الضابطة } & \\
\hline
\end{tabular}

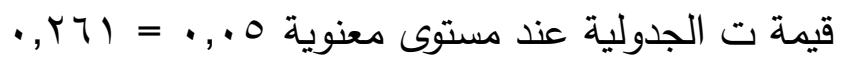

يتضح من جدول ( 1 - ع ) وجود فروق ذات دلالة إحصائية بين القياس القبلي والبعدي للمجموعتين التجريبية والضابطة لمتغير الوثب العريض من الثبات لصالح القياس البعدي وبلغت نسبة التحسن للمجموعة الضابطة ا9., ,ـ ٪ ، بينما بلغت نسبة التحسن للمجموعة التجريبية ب7ه, • 1 .

$$
\text { جدول ( }
$$

دلالة الفروق بين القياسين القبلي و البعدي للمجموعتين التجريبية و الضابطة

\begin{tabular}{|c|c|c|c|c|c|c|c|}
\hline \multirow{2}{*}{ الدلالة } & \multirow{2}{*}{ ت } & \multirow{2}{*}{ ف س } & \multicolumn{2}{|c|}{ بعدي } & \multicolumn{2}{|c|}{ قبلي } & \multirow{2}{*}{ العوثب العودي } \\
\hline & & & $\varepsilon \pm$ & س & $\varepsilon \pm$ & س & \\
\hline دالة & $1 ., 10 \leqslant-$ & $1 \leqslant, \varepsilon r q-$ & $\varepsilon, \mid \vee \varepsilon$ & $0 \leqslant$ & $r, 9 \vee V$ & rq,ovi & التجريبية \\
\hline دالة & 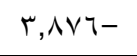 & $7, \vee \backslash \leq-$ & ס Tr, & $\leq 7,1 \leq r$ & $0, r 91$ & 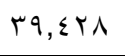 & الضابطة \\
\hline \multicolumn{5}{|c|}{ \% } & \multicolumn{2}{|c|}{ التجريبية } & نسبة \\
\hline \multicolumn{5}{|c|}{$\% \mid v, \cdot r \wedge$} & \multicolumn{2}{|c|}{ الضابطة } & التحسن \\
\hline
\end{tabular}
لمتغير الوثب العمودي (ن = ع 1)

$$
\text { قيمة ت الجدولية عند مستوى معنوية ه ., = = (ا7,, }
$$


يتضـــح مسن جـدول ( r - ع ) وجــود فـروق ذات دلالــة إحصــائية بـين القيـاس القبلـي والبعـدي للمجمـوعتين التجريبيـة والضـابطة لمتغيـر الوثـب العدـودي

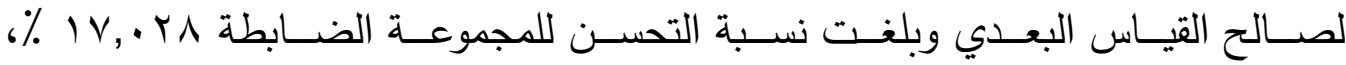

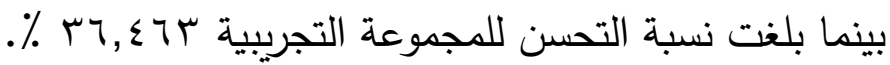

$$
\text { جدول ( ) }
$$

دلالة الفروق بين القياسين القبلي و البعدي للمجموعتين التجريبية و الضابطة

$$
\text { لمتغير زمن سباحة . . . } 1 \text { متر صدر (ن = ع ع 1) }
$$

\begin{tabular}{|c|c|c|c|c|c|c|c|}
\hline \multirow{2}{*}{ الالالة } & \multirow{2}{*}{ ت } & \multirow{2}{*}{ ف س } & \multicolumn{2}{|c|}{ بعدي } & \multicolumn{2}{|c|}{ قبلي } & \multirow{2}{*}{ صدر م م } \\
\hline & & & $\varepsilon \pm$ & س & $\varepsilon^{ \pm}$ & س س & \\
\hline دالة & $9,0 \wedge r$ & $0, \cdot \vee q$ & 1, & $\Lambda \cdot,|\vee|$ & $1, \cdot 14$ & $10, Y_{0}$ & التجريبية \\
\hline دالة & $1, \wedge 71$ & $1, \cdot r r$ & $1, \wedge \vee$. & $\Lambda \leq, 10 \wedge$ & $\cdot, 771$ & $10,1 \wedge$ & الضـابطة \\
\hline \multicolumn{5}{|c|}{$\% 0,90 \mathrm{~V}-$} & \multicolumn{2}{|c|}{ التجريبية } & نسبة \\
\hline \multicolumn{5}{|c|}{$\% 1,199-$} & \multicolumn{2}{|c|}{ الضابطة } & التحسن \\
\hline
\end{tabular}

قيمة ت الجدولية عند مستوى معنوية 0 ., = = (آץ, •

يتضح من جدول ( r - ع ) وجود فروق ذات دلالة إحصائية بين القياس القبلي والبعدي للمجموعتين التجريبية والضابطة لمتغير زمن سباحة . .. م صدر لصالح القياس البعدي وبلغت نسبة التحسن للمجموعة الضابطة 99 1, 1 ٪ ، بينما بلغت نسبة التحسن للمجموعة التجريبية 0,90V ٪. - دلالـــة الفـروق فــي القيـاس البعــدي بــين المجمــوعتين التجريبيــة والضـــابطة في متغيرات البحث.

$$
\text { جدول ( }
$$

\begin{tabular}{|c|c|c|c|c|c|c|c|c|}
\hline \multirow{2}{*}{ الدلالة } & \multirow{2}{*}{ ت } & \multirow{2}{*}{ ف ف } & \multicolumn{2}{|c|}{ الضابطة } & \multicolumn{2}{|c|}{ التجريبية } & \multirow{2}{*}{ القياس } & \multirow{2}{*}{ المتغير } \\
\hline & & & $\varepsilon^{ \pm}$ & س & $\varepsilon^{ \pm}$ & س & & \\
\hline
\end{tabular}

دلالة الفروق في القياس البعدي بين المجموعتين التجريبية الضابطة في متغير الوثب العريض من الثبات (ن = ع 1) 


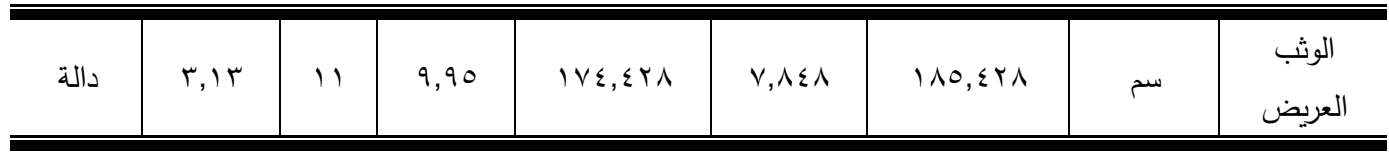

قيمة ت الجدولية عند مستوى معنوية 0 ., = = ו آץ,

يتضح من جدول ( ع - ع ) وجود فروق ذات دلالة إحصائية في القياس البعدي

بين المجموعتين التجريبية والضابطة لمتغير الوثب العريض من الثبات لصالح المجموعة

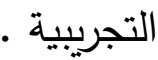

$$
\text { جدول ( }
$$

دلالة الفروق في القياس البعدي بين المجموعتين التجريبية و الضابطة

$$
\text { في متغير الوثب العمودي (ن = ع أ) }
$$

\begin{tabular}{|c|c|c|c|c|c|c|c|c|}
\hline \multirow{2}{*}{ الالاكة } & \multirow{2}{*}{ ت } & \multirow{2}{*}{ ف س } & \multicolumn{2}{|c|}{ الضابطة } & \multicolumn{2}{|c|}{ التجريبية } & \multirow{2}{*}{ وحدة القياس } & \multirow{2}{*}{ لمتغير } \\
\hline & & & $\varepsilon \pm$ & س & $\varepsilon \pm$ & س & & \\
\hline دالة & חו & $\vee, \wedge \circ \wedge$ & ס ז,r & $\leq 7,1 \leq r$ & $\varepsilon, 1 \vee \varepsilon$ & $0 \leqslant$ & سم & العمودي \\
\hline
\end{tabular}

يتضح من جدول ( 0 - §) وجود فروق ذات دلالة إحصائية في القياس البعدي

بين المجموعتين التجريبية والضابطة لمتغير الوثب العمودي لصالح المجموعة التجريبية .

$$
\text { جدول ( }
$$

\begin{tabular}{|c|c|c|c|c|c|c|c|c|}
\hline \multirow{2}{*}{ الالالة } & \multirow{2}{*}{ ت } & \multirow{2}{*}{ ف س } & \multicolumn{2}{|c|}{ الضابطة } & \multicolumn{2}{|c|}{ التجرببية } & \multirow{2}{*}{ وحدة } & \multirow{2}{*}{ المتغير } \\
\hline & & & $\varepsilon \pm$ & س & $\varepsilon \pm$ & س & & \\
\hline دالة & $V, 197-$ & 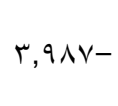 & $1, \lambda V$ & $\Lambda \varepsilon, 10 \Lambda$ & I,T & $\lambda \cdot,|v|$ & $\dot{H}$ & صدر \\
\hline
\end{tabular}

دلالة الفروق في القياس البعدي بين المجموعتين التجريبة و الضابطة

$$
\text { في متغير زمن سباحة ( . . 1) متر صدر (ن = ع 1) }
$$

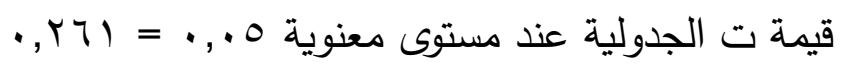


يتضح من جدول ( 1 - ع ) وجود فروق ذات دلالة إحصائية في القياس البعدي بين المجموعتين التجريبية والضابطة لمتغير زمن سباحة ( . (1) متر صدر لصالح

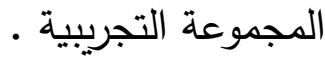

$$
\text { جدول ( }
$$

دلالة الفروق بين القياسين القبلي و البعدي للمجموعتين التجريبية و الضابطة لمتغير هرمون الروبامين (ن = ؛ 1 )

\begin{tabular}{|c|c|c|c|c|c|c|c|}
\hline \multirow{2}{*}{ الدلالة } & \multirow{2}{*}{ ت } & \multirow{2}{*}{ ف س } & \multicolumn{2}{|c|}{ بعدي } & \multicolumn{2}{|c|}{ قبلي } & \multirow{2}{*}{ الوثب العربض } \\
\hline & & & $\varepsilon \pm$ & س & $\varepsilon \pm$ & س & \\
\hline دالة & 0,90 & $\Upsilon \wedge, \Sigma) \Gamma$ & $r, r_{1}$ & TVV,TRT & $\cdot, Y \wedge$ & $r \cdot 9, r_{1}$ & التجريبية \\
\hline دالة & r,Tr & IV,rr & $r, 11$ & O Tr,TO & r,Or & $r \cdot 0, r r$ & الضابطة \\
\hline \multicolumn{5}{|c|}{$\% r \leq, T \leq$} & \multicolumn{2}{|c|}{ التجريبية } & مة ت م \\
\hline \multicolumn{5}{|c|}{$\% \vee, \vee \wedge$} & \multicolumn{2}{|c|}{ الضابطة } & \\
\hline
\end{tabular}

$$
\text { قيمة ت الجدولية عند مستوى معنوية } 0 \text {., = = (اדY, • }
$$

يتضح من جدول ( V - ع ) وجود فروق ذات دلالة إحصائية بين القياس القبلي والبعدي للمجموعتين التجريبية والضابطة لمتغير هرمون الروبامين لصالح القياس البعدي وبلغت نسبة التحسن للمجموعة الضابطة V,VA ٪ ، بينما بلغت نسبة التحسن للمجموعة

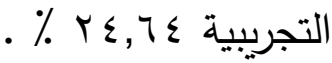

$$
\text { جدول ( } 1 \text { ( }
$$

\begin{tabular}{|c|c|c|c|c|c|c|c|}
\hline \multirow{2}{*}{ الدلالة } & \multirow{2}{*}{ ت } & \multirow{2}{*}{ ف س } & \multicolumn{2}{|c|}{ بعدي } & \multicolumn{2}{|c|}{ قبلي } & \multirow{2}{*}{ الوثب } \\
\hline & & & $\varepsilon \pm$ & س & $\varepsilon \pm$ & س & \\
\hline دالة & $0, \pi r$ & $r r, .$. & $\cdot, 79$ & $|\pi|, r \mid$ & $\cdot, 7 \leqslant$ & $|r \wedge, r|$ & التجريبية \\
\hline دالة & Tr,Tr & $\wedge, 94$ & $\cdot, 01$ & $1 \leqslant \varepsilon, r Y$ & $r, 01$ & & الضابطة \\
\hline \multicolumn{5}{|c|}{$\% \backslash \leq$, Y } & \multicolumn{2}{|c|}{ التجريبية } & نسبة \\
\hline \multicolumn{5}{|c|}{$\% ч, \mid \wedge$} & \multicolumn{2}{|c|}{ الضابطة } & التحسن \\
\hline
\end{tabular}

دلالة الفروق بين القياسين القبلي و البعدي للمجموعتين التجربيية و الضابطة لمتغير هرمون السيترولين (ن = ؛ 1 ) 


$$
\text { قيمة ت الجدولية عند مستوى معنوية } 0 \text {., = = آبץ, • }
$$

يتضح من جدول ( r - ع ) وجود فروق ذات دلالة إحصائية بين القياس القبلي والبعدي للمجموعتين التجريبية والضابطة لمتغير هرمون السيترولين لصالح القياس البعدي وبلغت نسبة التحسن للمجموعة الضابطة ^1,7 ٪، بينما بلغت نسبة التحسن للمجموعة هوبة

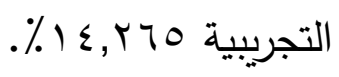
مناقشة وتفسير نتائج البحث : - باستعراض معطيات الجداول رقم ( 1 - ع ) ) ، ( ع - ع ) وكذلك الأشكال البيانية

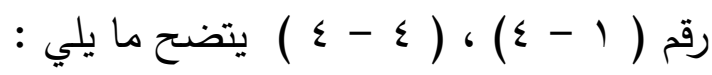
توجد فروق بين القياسين القبلي و البعدي للمجموعتين التجريبية و الضابطة لمتغير الوثب العريض من الثبات لصالح القياس البعدي فقد بلغت نسبة التحسن للمجموعة الضابطة (9),یء٪ ، بينما بلغت نسبة التحسن للمجموعة التجريبية

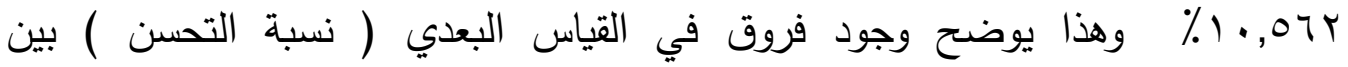
المجموعتين التجربية و الضابطة لصالح المجموعة التجريبية ( المجموعة التي استخدمت تدريبات المرونة النفسية) وهذا يرجع إلى أن برنامج تدريبات المرونة النفسية المقترح أثر إيجابيا على القدرة العضلية للرجلين، وذلك عن طريق تحديد الهدف وتخيلة ومساعد التدريبات العقلية

- وباستعراض معطيات الجداول رقم ( r - ع ) ، (

$$
\text { رقم ( ) }
$$

توجد فروق بين القياسين القبلي و البعدي للمجموعتين التجريبية و الضابطة لمتغير الوثب العمودي من الثبات لصالح القياس البعدي فقد بلغت نسبة التحسن

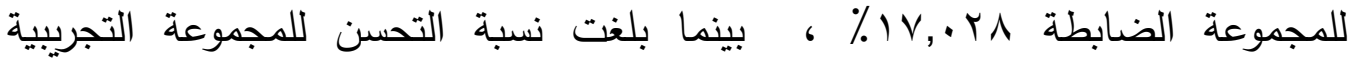
سדء, דس\% وهذا يوضح وجود فروق في القياس البعدي ( نسبة التحسن ) للمجموعتين 
التجريبية و الضابطة لصالح المجموعة التجريبية (المجموعة التي استخدمت تدريبات

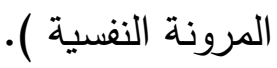

وهذا يرجع إلى أن تمرينات المرونة النفسية المستخدمة في الاتجاه الرأسي أثرت إيجابيا على القدرة العضلية للرجلين و مسافة الوثب العمودي من الثبات لدى سباحي المجموعة التجريبية (المجموعة التي استخدمت تدريبات المرونة النفسية)، وهذا يتقق مع ما أشارت إليه نتائج الدراسات السابقة فأشارت الى التركيز في الاداء يسهم بشكل كبير في تحسين القدرات البدنية والمهارية - وباستعراض معطيات الجداول رقم ( ب - ع ) ، ( 7 - ع ) ) وكذلك الأشكال البيانية

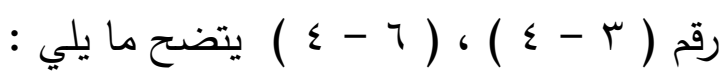

توجد فروق بين القياسين القبلي و البعدي للمجموعتين التجريبية و الضابطة لمتغير زمن سباحة . .1 متر صدر لصالح القياس البعدي فقد بلغت نسبة التحسن

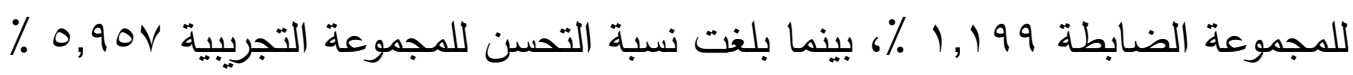
وهذا يوضح وجود فروق في القياس البعدي (نسبة التحسن) بين المجموعتين التجريبية والضابطة لصالح المجموعة التجريبية (المجموعة التي استخدمت تدريبات المرونة النفسية.

وهذا يرجع إلى أن برنامج تدريبات المرونة النفسية المقترح أثر إيجابيا على

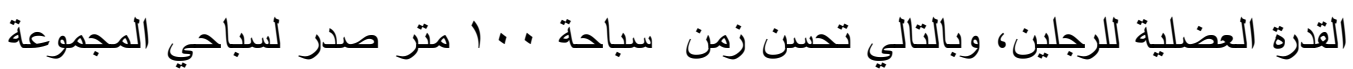
التجريبية \}المجموعة التي استخدمت تدريبات المرونة النفسية ج ، وهذا يتفق مع ما أشارت

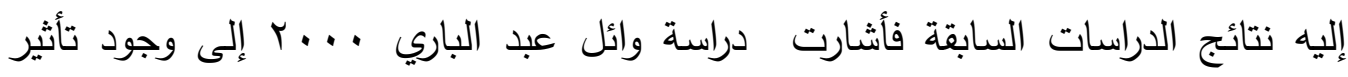
إيجابي لتمرينات الوثب العميق على الطرف السفلي لعضلات السباحين وزمن البدء في سباحة الزحف على البطن ، وكذلك دراسة إيهاب إسماعيل ... . . التي أوضحت أن تدريبات (الوثب العميق) مع تركيز الانتباه تؤدي إلى تتمية القدرة العضلية للرجلين مما يؤثر ايجابيا على زمن رد الفعل ومسافة الطيران وزمن Or م سباحة زحف على الظهر ، و دراسة دينا سعيد ا .. التي أوضحت أن البرنامج المقترح له تأثير ايجابي في زيادة 
نسبة التحسن للقدرة العضلية للرجلين عن المجموعة الضابطة وكذلك في زيادة مسافة البدء وتحسين زمن الأداء في سباحة الظهر ، ودراسة يحيى ذكريا ا ... التي أوضحت أن استخدام تدريبات البليومترك المصاحبة للاعداد العقلى أفضل وأكثر تأثيرا من تدرببات الأتقال على تتمية القدرة العضلية والسرعة وكذلك تحسين المستوى الرقمي لسباحي الفراشة، ودراسة دينا المتولي ع ... التي أوضحت أن استخدام الزعانف الأحادية ( المنوفين ) في برامج التدريب يساعد على زيادة نسبة التحسن في المرونة والقدرة العضلية للرجلين وكذللك تحسين المستوى الرقمي للسباحين الناشئين في سباحة الدولفين ، وكذلك دراسة مصطفى راضي ج × . . التي أوضحت أن استخدام تدربات البليومترك يؤثر ايجابيا على القوة الانفجارية وبالتالي على مهارة البدء من أسفل لسباحي الزحف على الظهر وعلى زمن هام سباحة زحف على الظهر • وهذا يحقق صحة الفرضين الأول والثاني : - - توجد فروق دالة إحصائيا بين القياس القبلي والقياس البعدي للقدرة العضلية والمستوى الرقمي لصالح القياس البعدي للمجموعة الضابطة . - - مد فروق دالة إحصائيا بين القياس القبلي والقياس البعدي للقدرة العضلية والمستوى الرقمي لصالح القياس البعدي للمجموعة التجريبية . - وباستعراض معطيات الجداول رقم الجداول ( ع - ع ) ، ( وكذلك الأشكال البيانية رقم ( ع - ع ) ، ( 0 - ع ) ، ( 1 - ع ) يتضح ما يلي : توجد فروق بين القياس البعدي للمجموعتين الضابطة و التجربيية لمتغيرات البحث ( الوثب العريض من الثبات - الوثب العمودي - زمن سباحة . . . متر صدر ) لصالح المجموعة التجريبية فكانت قيمة ( ت - T-test ) لمتغير الوثب العريض من

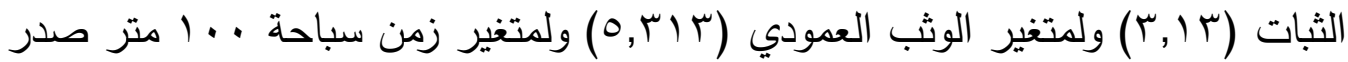
$\cdot(\vee, 197-)$ 
وترجع الباحثة هذه النتائج إلى استخدام لتمرينات الاسترخاء وتأثيرها الايجابي على اندفاعية الأداء ( تخفيض درجة التوتر - تركيز الانتباة) والتي أثرت ايجابيا على هنى تحسين مستوى أداء سباحة ــ متر زحف لادى عينة البحث.

ويشير خالد عبد الرازق السيد (1 . .rم) أن توجد علاقة طردية بين التدريبات الرياضية وتمرينات الاسترخاء حيث تزيد تدربات الاسترخاء في الوصول للسباح إلى لـ لرجي

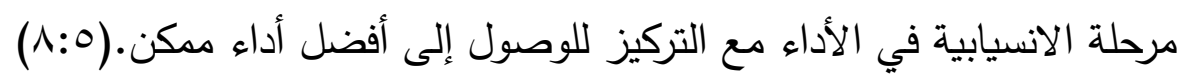

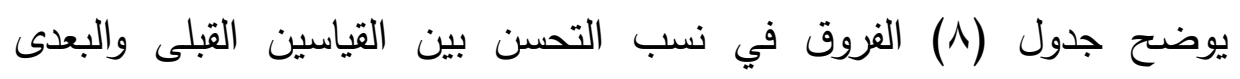
لاندفاعية الأداء ( تركيز الانتباه وتخفيض درجة التوتر ) لدى منتخب السباحة لجامعة

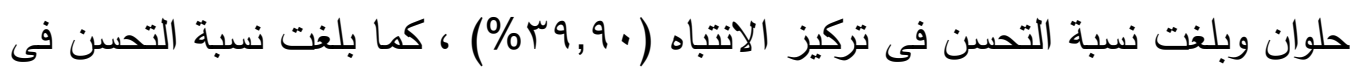

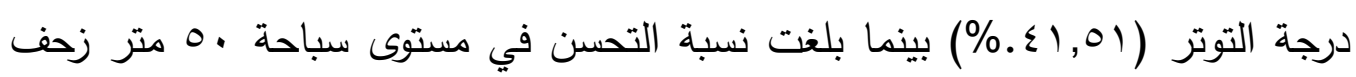
. $(\% r q, r r)$

ويرجع الباحث هذه النتائج إلى التأثير الايجابى لتمرينات الاسترخاء والمستخدمة فى اندفاعية الأداء ( تركيز الانتباه وتخفيض درجة التوتر ) وتأثيرها على مستوى أداء

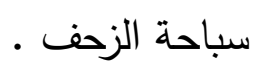

حيث تبرز أهمية تمرينات المرونة النفسية بالنسبة للفرد فى إنها تكسبه قوة الإرادة

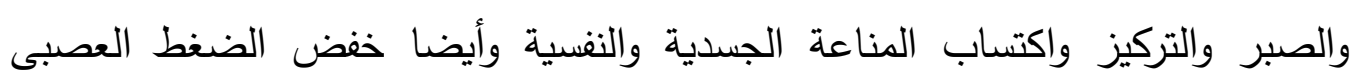

$$
\text { والتوتز الواقع عليه (Y V : V : (Y) }
$$

إلى أن تدريبات الاسترخاء التدريجى تحقق اكتساب مهارة التخلص من التوتر

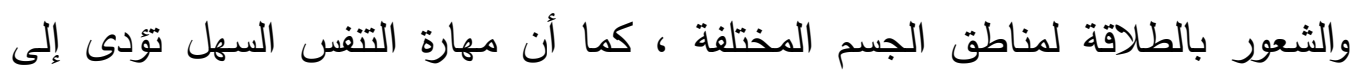
اكتساب مهارة الاسترخاء للرياضيين ، كما أشار إلى أن التدريب الاسترخائى يساهم

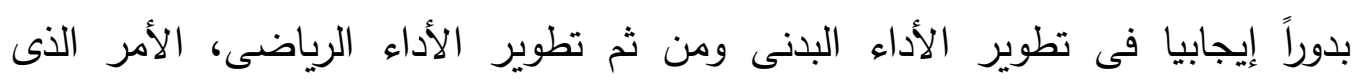

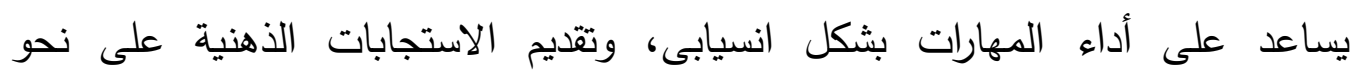

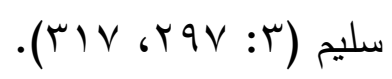


أن الاسترخاء يؤدى إلى خفض تأثير الاستجابة إلى الضغط العصبى والمساعدة على الوصول إلى المستوى الأمثل من التوتر ومنع تراكم الضغط العصبى بواسطة العمل على الوصول إلى مستوى منخفض من التوتر والوصول إلى درجة من الاسترخاء العميق

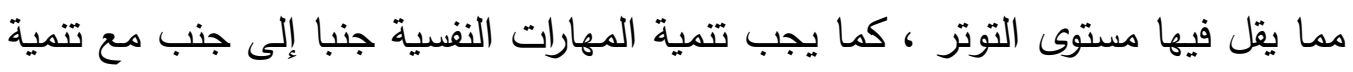
الأداء المهاري ، وأن ممارسة تدريبات الاسترخاء تعمل على تحسين مستوى الأداء

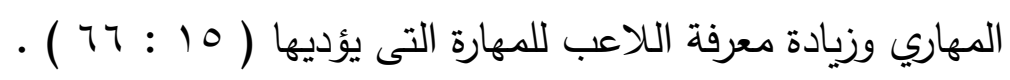
وهذا يوضتح صحة الفرض الثالث :

توجد فروق دالة إحصائيا في القياس البعدي للقدرة العضلية والمستوى الرقمي بين

المجموعتين الضابطة والتجريبية لصالح المجموعة التجرببية. يتضح من جدول ( r - ع ) وجود فروق ذات دلالة إحصائية بين القياس القبلي والبعدي للمجموعتين التجريبية والضابطة لمتغير هرمون السيترولين لصالح القياس البعدي

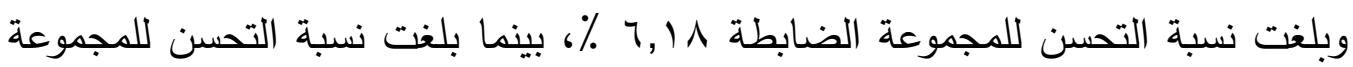

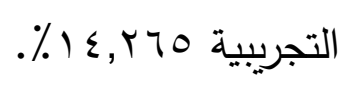

إن الالتزام بممارسة التمارين البدنية، بالنسبة للكثيرين منا، يكاد يكون قرارا صعبا. ووفقا لمراكز مراقبة الأمراض والوقاية منها (CDC) الأميركية فإن النشاط البدني المنتظم يمكن أن يقلل من خطر الإصابة بأمراض خطيرة، مثل مرض السكري من النوع الثاني، والسرطان، وأمراض القلب والأوعية الدموية. ووفقا لبحث نشر قبل سنتين لفريق طبي ترأسه البروفسور ألكسكساي في كرافيتز رئيس قسم أمراض السكري والغدد الصماء والسمنة في المعهر الوطني للسكري وأمراض الجهاز الهضمي والكلى (NIDDK) حول السبب في أن الحيوانات السمينة تعاني من صعوبة في ممارسة النشاط البدني - فقد وجد أن هناك رابطا بين نقص الدوبامين ونقص النشاط البدني لدى الفئران.(00)

أما الدوبامين، فإنه بالإضافة إلى ذلك، يؤثر على كيفية تحريك الشخص، حيث لا توجد أي صلة واضحة لدور السيروتونين في الحركة. ويمكن أن يكون لنقص الدوبامين 
تأثير كبير على نوعية حياة الثخص، مما يؤثر عليه جسدياً وذهنياً. ويرتبط العديد من اضطرابات الصحة العقلية بمستويات منخفضة من الدوبامين. كما تم ربط حالات طبية أخرى، بما في ذلك مرض باركنسون، بانخفاض مستوى الدوبامين.

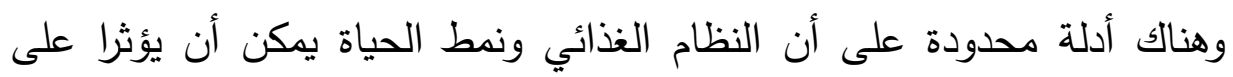
مستويات الدوبامين الذي يقوم الشخص بإنشائه وينقله في أرجاء الجسم. قد تساعد بعض بـ الأدوية وبعض العلاجات في تخفيف الأعراض، ولكن يجب على الشخص دائماً التحدث

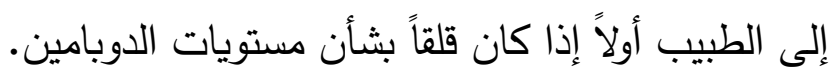
وهذا يوضح صحة الفرض الرابع : توجد فروق دالة إحصائيا في القياس البعدي هرموني الروبامين والسيروتلين بين المجموعتين الضابطة والتجرببية لصالح المجموعة التجريبية الاستخلاصات والتوصيات :

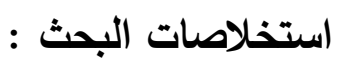

ا . بلغت نسبة التحسن للمجموعة التجريبية (المجموعة التي استخدمت تدربات المرونة النفسية) ro7, • 1 ٪ في متغير الوثب العريض من الثبات بينما

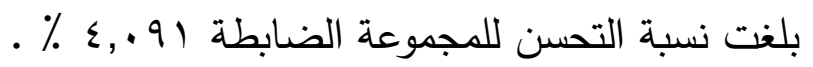
r. بلغت نسبة التحسن للمجموعة التجريبية ( المجموعة التي استخدمت تدريبات المرونة النفسية) بحـ, بـ ٪ في متغيرالوثب العمودي من الثبات بينما بلغت

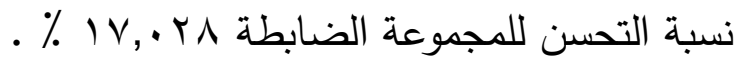
r. بلغت نسبة التحسن للمجموعة التجريبية (المجموعة التي استخدمت تدريبات المرونة النفسية) - 0,90V ٪ في متغير زمن سباحة . . 1 متر بينما بلغت

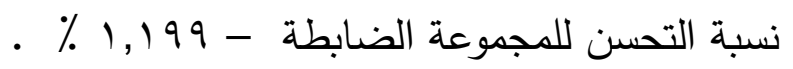
ع. بلغت نسبة التحسن للمجموعة التجريبية ( المجموعة التي استخدمت تدريبات

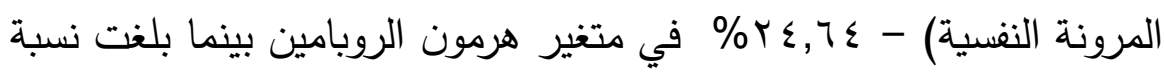

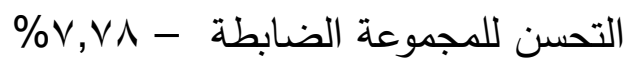


0. بلغت نسبة التحسن للمجموعة التجريبة ( المجموعة التي استخدمت

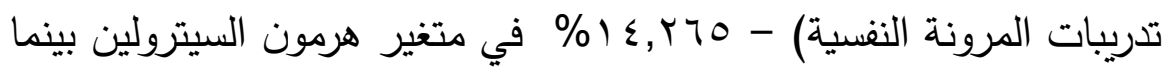

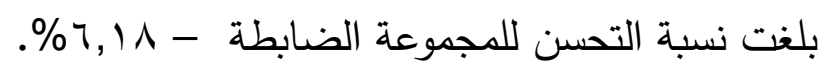

\section{توصيات البحث :}

ا.استخدام برنامج المرونة النفسية المقترح لتطوير القدرة العضلية للرجلين لسباحي

الصدر ، حيث أنه يؤثر ايجابيا على المستوى الرقمي لزمن سباحة . . . متر صدر . r.استخدام اختباري الوثب العريض من الثبات والوثب العمودي للسباحين كمؤشر

لتطوير القدرة العضلية بالاتجاهين الأفقي والرأسي . r. استخدام برنامج المرونة النفسية على السباحات الأخرى . ع ـ استخدام برنامج النفسية في المراحل السنية المختلفة . 


\section{المراجــع}

\section{المراجع العربية:}

1-أحمد عبد المنعم باشا (11 • rم) الصلابة العقلية لدى لاعبى المستويات الرياضية العليا ،رساله ماجستير غير منشورة ،كلية التربية الرباضية ، جامعه طنطا . Y-أحمد محمد محمد، تامر محمد محمود (1 ...rم) : السمات الدافعية ودافعية الانجاز لاى لاعبى الملاكمة والمصارعة (دراسة مقارنة) ، المجلة العلمية للتربية البدنية والرياضية ،عدد (VV)، كلية التربية الرياضية ، جامعة كفر الثيخ ب-أسامة كامل راتب (10 • r م) : الاعم النفسى للناشئ (المدرب - الأباء) ، دار الفكر

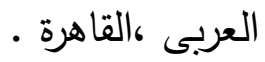

ع- أمانى وحيد إبراهيم( ^ . . r ) ): الصلابة النفسية والسمات الدافعية الرياضية وعلاقتها

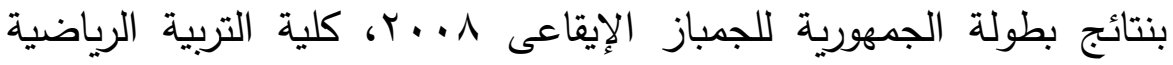
للبنين، جامعة حلوان ،المجلة العلمية للتربية البدنية والرياضية ،عدد (به). ه-أمل على خليل حسن( V. . r.م): الصلابة النفسية وعلاقتها بمواجهة الضغوط لدى سباحى المسافات القصيرة ، كلية التربية الرياضية للبنين، جامعة حلوان ،المجلة العلمية للتربية البدنية والرياضية ،عدد (•.0).

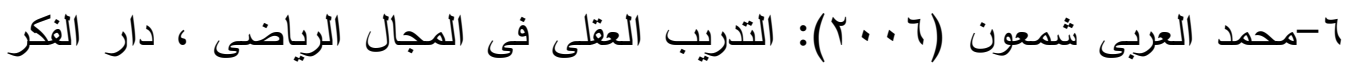

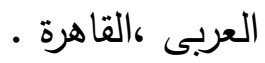

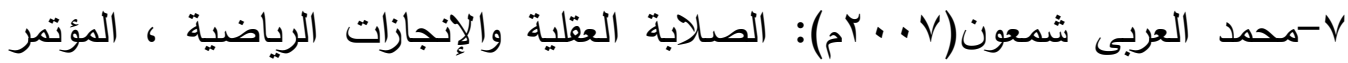
العلمى السنوى بقسم علم النفس الرياضى (الرعاية النفسية للرياضيين) ، كلية التربية الرياضية ، جامعة حلوان • 1-محمد حسن علاوى(9 . . ץ): مدخل فى علم النفس الرياضى ، مركز الكتاب للنشر ، الطبعة السابعة. 
9-محمد لطفى حسين ج + . ب:الإنجاز الرياضى وقواعد العمل التدريبى رؤية تطبيقية ،

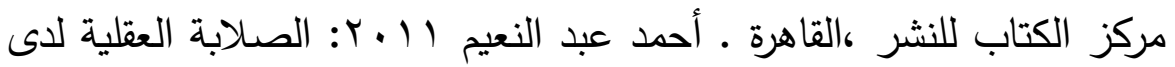
لاعبى ولاعبات المستويات الرياضية العالية ،رسالة ماجستير ،جامعة طنط • 1-محمد محمود متولى (0. . rم) : فاعلية تدريب الصلابة العقلية على إستراتيجيات الأداء ودقة تصويب الكرات الثابتة لناشئ كرة القدم ، بحث منشور ، مجلة بحوث التربية الشاملة ، المجلد الثانى ،النصف الأول ، كلية التربية الرياضية

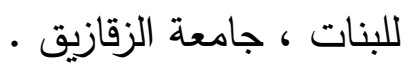

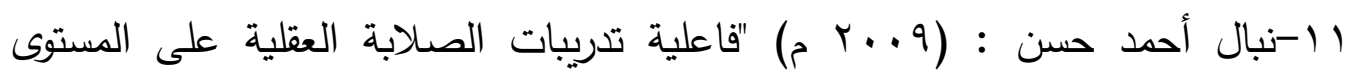
الرقمى للاعبات قذف القرص "،بحث منشور ، المؤتمر الإقليمى الرابع للمجلس الدولى للصحة والتربية البدنية والترويح والرياضة والتعبير الحركى التى

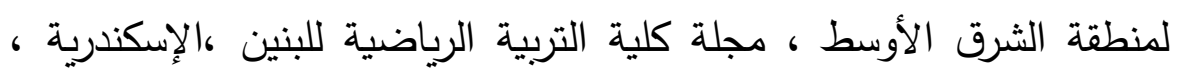
أبوقير - n

r ا-نجلاء البدرى نور الدين محمد (r +. r م) : الثقة الرياضية كسمة وكحالة والدافعية للإنجاز وعلاقتها بالمستوى الرقمى لسباق ·. . ام حواجز ، كلية التربية الرياضية للبنات ، جامعة حلوان ، رسالة ماجستير ، غير منشورة

rا-يحى محمد محمد (ع ..rم): علاقة دافعية الإتجاز وبعض مظاهر الانتباه وقلق المنافسه بالمستوى الرقمى لدى سباحى المنافسات ، رساله دكتوراه ، غير

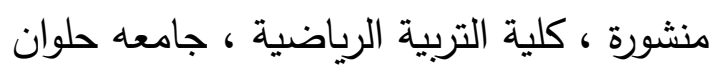

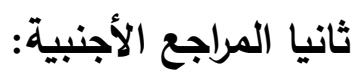

14-Fulgham, A., (2004): Implementing a psychological skills training program in high school volleyball athletes, phD thesis, faculty of sports science, Missouri Western State University, USA. 
15-Matt,J (2005) : Sport Psychology a Students Hand Book ; rout ledge.U.S.A

16-Middelton, S.(2007): mental toughness conceptualization and measurement .Coaching Review.

17- Simon C. Middelton, Herb W. Marsh , Andrew J . Martin , Garry E. Richard, and clark perry (2004): Discoverring mental toughness , A Gualitative study of mental toughness in Elite Athle, Third international Biennial, self Researcl conference, self concet, motivation and identity . where to from here ? July 4-7, Berlin , Germany.

18-triathlon Canada(2006): triathlon competition introduction, coaching course manual . Toronto, on triathlon Canada. 